\title{
BMJ Open How health service delivery guides the allocation of major trauma patients in the intensive care units of the inclusive (hub and spoke) trauma system of the Emilia Romagna Region (Italy). A cross- sectional study
}

\author{
Arturo Chieregato, ${ }^{1}$ Annalisa Volpi, ${ }^{2}$ Giovanni Gordini, ${ }^{3}$ Chiara Ventura, ${ }^{4,5}$ \\ Marco Barozzi, ${ }^{6}$ Maria Luisa Rita Caspani, ${ }^{2}$ Andrea Fabbri, ${ }^{7}$ Anna Maria Ferrari, ${ }^{8}$ \\ Enrico Ferri, ${ }^{3}$ Aimone Giugni, ${ }^{3}$ Massimiliano Marino, ${ }^{9}$ Costanza Martino, ${ }^{10}$ \\ Mario Pizzamiglio, ${ }^{11}$ Maurizio Ravaldini, ${ }^{10}$ Emanuele Russo, ${ }^{10}$ Laura Trabucco, ${ }^{8}$ \\ Susanna Trombetti, ${ }^{5,12}$ Rossana De Palma ${ }^{5,13}$
}

To cite: Chieregato A, Volpi A, Gordini $\mathrm{G}$, et al. How health service delivery guides the allocation of major trauma patients in the intensive care units of the inclusive (hub and spoke) trauma system of the Emilia Romagna Region (Italy). A cross-sectional study. BMJ Open 2017;7:e016415. doi:10.1136/ bmjopen-2017-016415

- Supplement Table 1 Trauma system organization and population distribution, average data peryear from 2007 to 2012. Data source http://statistica. regione.emilia-romagna. it/). Data are averagedovert the years and thus the cumulative sums of the partial amounts do not correspondto the total. Supplement Table 2Types of hospitals, * not inCesenaSupplement Figure 1 Study case material

- Prepublication history and additional material for this paper are available online. To view, please visit the journal (http:// dx.doi.org/bmjopen-2017016415).

Received 2 March 2017 Revised 31 May 2017 Accepted 20 July 2017

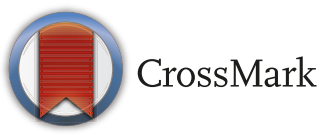

For numbered affiliations see end of article.

Correspondence to MD Arturo Chieregato; arturo.chieregato@gmail.com

\section{ABSTRACT}

Objective To evaluate cross-sectional patient distribution and standardised 30-day mortality in the intensive care units (ICU) of an inclusive hub and spoke trauma system.

Setting ICUs of the Integrated System for Trauma Patient Care (SIAT) of Emilia-Romagna, an Italian region with a population of approximately 4.5 million.

Participants 5300 patients with an Injury Severity Score (ISS) >15 were admitted to the regional ICUs and recorded in the Regional Severe Trauma Registry between 2007 and 2012. Patients were classified by the Abbreviated Injury Score as follows: (1) traumatic brain injury (2) multiple injuriesand (3) extracranial lesions. The SIATs were divided into those with at least one neurosurgical level II trauma centre (TC) and those with a neurosurgical unit in the level I TC only.

Results A higher proportion of patients (out of all SIAT patients) were admitted to the level I TC at the head of the SIAT with no additional neurosurgical facilities (1083/1472, 73.6\%) compared with the level I TCs heading SIATs with neurosurgical level II TCs (1905/3815; 49.9\%). A similar percentage of patients were admitted to level I TCs (1905/3815; 49.9\%) and neurosurgical level II TCs $(1702 / 3815,44.6 \%)$ in the SIATs with neurosurgical level II TCs. Observed versus expected mortality (OE) was not statistically different among the three types of centre with a neurosurgical unit; however, the best mean $\mathrm{OE}$ values were observed in the level I TC in the SIAT with no neurosurgical unit.

Conclusion The Hub and Spoke concept was fully applied in the SIAT in which neurosurgical facilities were available in the level I TC only. The performance of this system suggests that competition among level I and level II TCs in the same Trauma System reduces performance in both. The density of neurosurgical centres must be considered by public health system governors before implementing trauma systems.

\section{Strengths and limitations of this study}

The study is based on a 7-year institutional prospective cross-sectional data collection, including 30-day mortality data, relating to an entire Italian Region. Although the data were gathered in a specific Italian region with a well-established public health system, they are potentially generalisable to other densely populated countries with a predominance of publicly delivered healthcare services.

- The association between a higher number of neurosurgical centres and greater competition in patient allocation must be considered with caution because several potential sources of differences among intensive care units of the trauma system and trauma centres were not recorded.

- Considering the highly selected setting and similarities in the basic standard of care among centres, a larger sample is probably needed to detect any minor differences in outcome related to final trauma patient allocation.

\section{BACKGROUND}

Trauma is a major issue for society and a challenge for health policy-makers. In Italy, it is chiefly associated with road accidents. ${ }^{1-4}$ Regionalised trauma systems have been designed in many countries to provide a coordinated, organised response to injury. ${ }^{5}$ Concentrating patients in a few level I trauma centres (TC) to ensure prompt, specialised care should improve patient outcomes. ${ }^{5}$ Health authorities in several countries have used guidelines to designate hospitals as level I to IV TCs. ${ }^{6}$ There 
is a general consensus that level I TCs should admit at least 200 patients with major trauma per year. ${ }^{57}$

Currently, most regional trauma systems in the USA are based on the 'exclusive' design, but this prevents non-TC acute care facilities from participating in the treatment of less severe trauma patients, with the risk of expertise at non-TCs falling below critical levels. By contrast, Europe - which is more urbanised and has a higher density of hospitals - more frequently adopts an 'inclusive' model, encompassing non-TC hospitals (spoke centres) that care chiefly for less severe trauma. ${ }^{8}$ In this system, level 1 TCs (hubs) are central to trauma system organisation. ${ }^{8}$ They directly admit the patients who appear most severe at the scene and indirectly receive those who are undertriaged at first admission or who deteriorate after admission to a spoke centre.

In 2002, the regional health service of Emilia Romagna, in the north of Italy, designed three trauma systems, headed by three level I TCs, based on geographic location, previous organisational history and presence of clinical expertise (DGR 1267/2002) ${ }^{910}$ The organisations are referred to as 'Sistema Integrato Assistenza Traumi (SIAT: Integrated System for Trauma Patient Care)', each representing a separate, specific trauma system. In addition to a level I TC, two of these SIATs also included level II TCss with neurosurgical units. Considering the importance of traumatic brain injury (TBI) in trauma patients, it could be that these neurosurgical units centralise patients who would otherwise have been admitted to level I TCs.

The aim of this study was to describe access to intensive care by major trauma patients, within the various SIATs, 10 years after establishment of Emilia Romagna's Integrated System, and to discuss whether the availability of neurosurgical facilities may have influenced this process.

\section{MATERIAL AND METHODS}

\section{Setting}

Emilia-Romagna is an Italian region with a population of approximately 4.5 million (figure 1 and online supplement appendix table 1$).{ }^{11}$

The 'inclusive' model of trauma care included community and teaching hospitals not dedicated exclusively to trauma. All were linked to a dedicated Emergency Medical Service, including a helicopter. The SIAT characteristics are described in the appendix (see online supplementary appendix table 2). ${ }^{6}$ The underlying philosophy of the inclusive hub and spoke trauma system is that level I TCs function as hubs within highly specialised hospitals and other level II TC facilities serve as 'spokes'. Some level II TCs have neurosurgical units. The SIATs differ from each other in that one of them has no neurosurgical level II unit (Romagna) while neurosurgical units are present in the other two.

In summary, the trauma system is organised according to:

Level I TCs: Bologna Maggiore, Parma, Cesena hospitals;

- three subtypes of centre:

- Level II TCs with neurosurgery: Modena Baggiovara, Ferrara, Reggio Emilia hospitals;

- Level II TCs with no neurosurgery: Rimini, Riccione, Forlì, Ravenna, Faenza, Lugo, Piacenza hospitals

- two subtypes of SIAT;

- SIAT with a neurosurgical level II TC;

- SIAT with no neurosurgical level II TC.

The system embraces the concept of back transferring patients from the hub to the spoke, once they have been stabilised and specialist problems have been solved. ${ }^{12}$ The

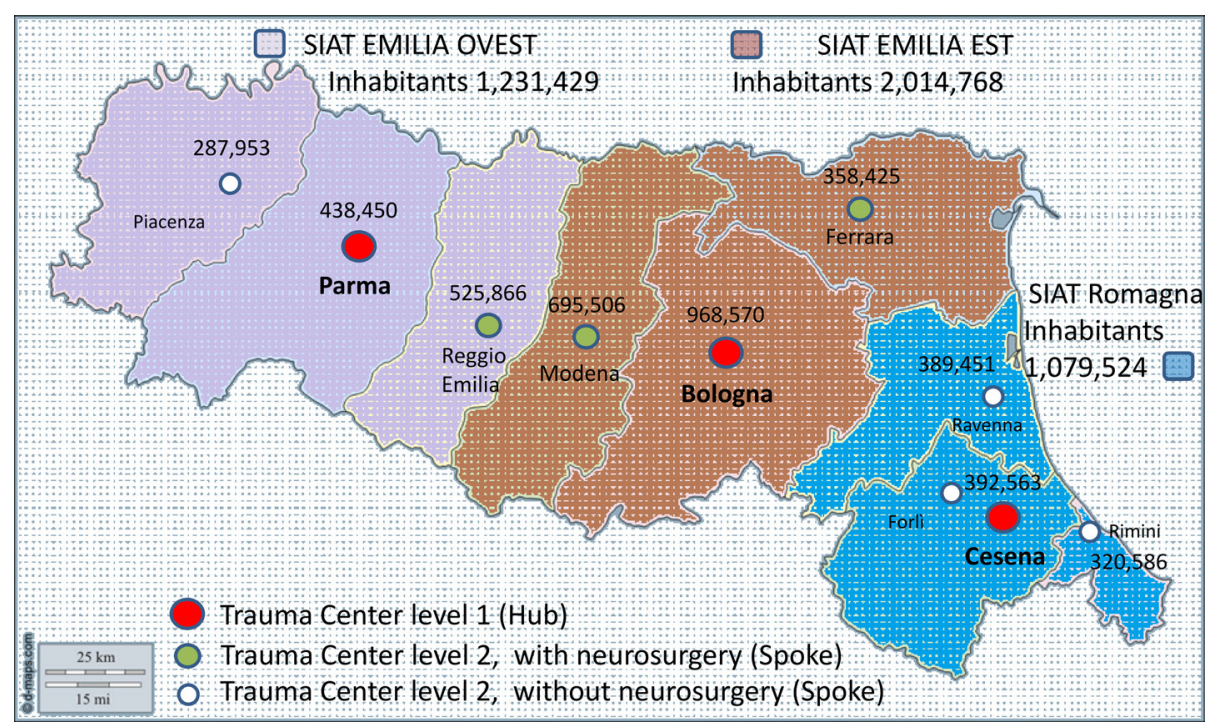

Figure 1 Simplified map of the Emilia Romagna region. The territory is divided into three SIATs and the central location of the three corresponding trauma centres level I (hubs) is reported. The population of each SIAT and each district referring to the level II trauma centre (spoke hospital) are described. The location and characteristics (neurosurgical versus nonsurgical) of the Level II trauma centres (spoke) are reported. SIAT, Integrated System for Trauma. 
intensive care unit (ICU) network is further supported by a network of rehabilitation units. ${ }^{13}$

In 2002 protocols to describe direct access from the scene to the level I TC and secondary referral from level II TCs were drawn up in each of three trauma systems. However, Romagna has been implementing telemedicine for TBI since the 1990s. ${ }^{1415}$

Since 2007, data on the severity of patient admissions in the Emilia Romagna region have been prospectively collected by the three level I TCs and 10 other spoke hospitals in the regional severe trauma registry (Registro Regionale Traumi Gravi (RRTG)). ${ }^{16}{ }^{17}$ The system has been regularly monitored by a commission which checks data and implements system organisation. ${ }^{18}$

\section{Case material}

The cross-sectional study was conducted using data from the RRTG. The case material analysed for the study consisted of consecutive cases collected from 2007 to 2012 (see online supplementary appendix figure 1). The criteria for inclusion in the registry was traumatic injury with an Injury Severity Score (ISS) greater than 15 or admission to an ICU. ${ }^{19}{ }^{20}$ Consequently, a potential source of bias is that patients admitted to the regular ward were not considered in the study. Injury severity was coded according to the Abbreviated Injury Score 1990 (AIS) (1998 update) by a trained coder at each hospital. Training was self-managed by the regional authorities, with no official certification by the Association for the Advancement of Automotive Medicine.

\section{Descriptive analysis of patient distribution}

Patients can be transferred from one hospital to another within the trauma system but are recorded in the registry only once. The following attribution criteria were applied for registry entries: (1) the first admitting hospital and (2) the data recorded in the ward providing the most intensive therapy, in said hospital.

Patients were also classified in three categories by type of anatomical lesion. The objective was to identify patients with clinically relevant extracranial injuries, those with clinically relevant cranial or spinal injuries and those with both clinically relevant extracranial or cranial/ spinal injuries.

We used an a priori AIS cut-off of $<3$ and $\geq 3$ to classify non-relevant or relevant clinical lesions, respectively. An AIS cranial score $\geq 3$ was used to classify moderate or severe TBI, ${ }^{21-24}$ although this differs from the conventional classification. ${ }^{25} 26$

Accordingly, the patients were classified as follows:

- Patients with moderate or severe TBI and/or cervical spine injury: with an AIS cranial score value $\geq 3$ and an AIS extracranial score;

- Patients with severe multiple injuries including TBI and/or cervical spine injury: with extracranial and cranial lesions, both with AIS score $\geq 3$;

- Patients with extracranial lesions: with at least one extracranial AIS score of $\geq 3$ and a cranial AIS of $<3$.
Patients' clinical severity was described by the ISS, the AIS and the Glasgow Coma Scale (GCS).$^{25}$ Comorbidities were assessed by the Charlson Score Index. ${ }^{27}$

The data were reported descriptively. Continuous variables were expressed as mean, SD, median and range. Age was described both as a continuous value and in three categories according to cut-off ages of 15 and 70 years.

\section{Standardised mortality}

Thirty-day patient mortality was standardised according to several covariates using a hierarchical logistic regression model. This has already been published by our group. ${ }^{28}$ The model included the following covariates: age (continuous variable), ISS (continuous variable), gender (continuous variable), mechanism of injury (traffic accident, fall, penetrating, other, missing or unknown), motor GCS (continuous variable), systolic blood pressure (0-49 mm Hg, 50-89 mm Hg, 90-179 mm Hg, $\geq 180 \mathrm{~mm}$ $\mathrm{Hg})$. Taking the sum of observed deaths and the sum of the individual probability of death (from 0 to 1 , obtained by solving the logistic equation), we determined the observed/expected ratio (OE).$^{29}$ The $\mathrm{OE}$ was calculated separately for patients with moderate or severe TBI or cervical spine injury and patients with severe multiple injuries, and was compared among (1) level I TC in SIATs without a neurosurgical level I TC (Cesena Hospital), (2) level I TCs in SIATs with neurosurgical spokes (Bologna Maggiore and Parma hospitals), and (3) neurosurgical level II TCs (Modena Baggiovara, Ferrara, Reggio Emilia hospitals).

All analyses were carried out with the SAS V.8.2 System (SAS Institute). The study was conducted in adherence to regional privacy regulation number 3 of Emilia-Romagna dated 24 April 2006 (Title: Sensitive data processing) and act number 1 of 30 May 2014, which was still in force at the time of writing. In addition, each patient had an anonymous identifier assigned by the Regione Emilia Romagna to enable each individual to be tracked over time without jeopardising patient privacy.

\section{RESULTS}

After applying the inclusion criteria, 5300 patients were eligible for the study. However, details on the AIS categories were available for only 5287 patients.

General and specific characteristics of patients (reported in table 1).

Younger patients were more frequently admitted to level I TCs and older patients to level II TCs. Paediatric traumas were chiefly centralised at level I TCs, particularly patients aged $<15$ (in $91 \%$ of cases between 0 and 2 years, $80 \%$ between 3 and $8,76 \%$ between 9 and 11 years, and $60 \%$ aged 12 years and over). A slightly lower number of patients aged over 80 years were treated in level I TCs (48\% in level I and 52\% in level II TCs). This observation is more clearly summarised in figure 2.

Patients admitted to level I TCs less frequently appeared to have comorbidities. A higher percentage of patients 


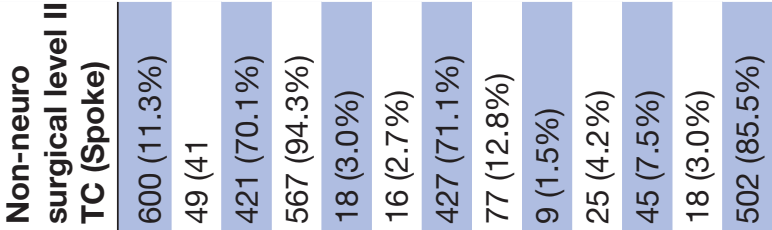

\section{$\overline{\widetilde{J}}$}

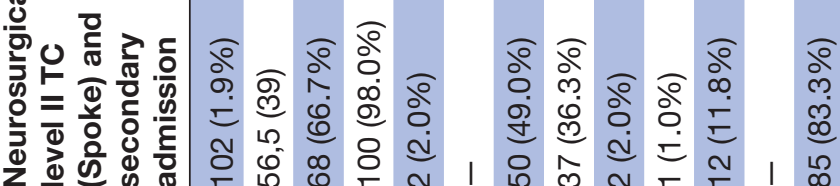

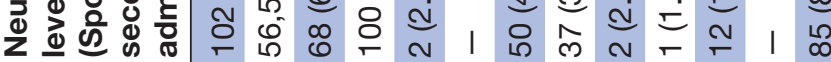

$\overline{\mathbb{S}}$

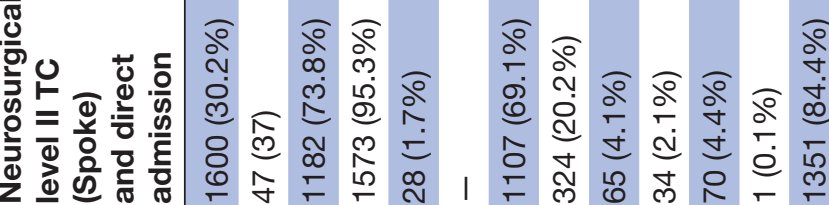

올 $\frac{?}{1}$

0. 二

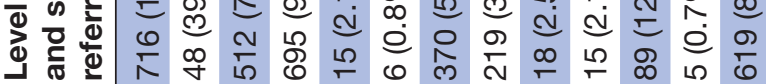

盗

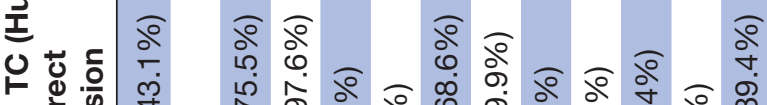

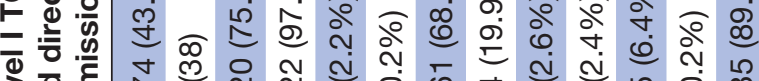

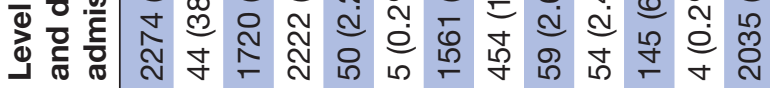

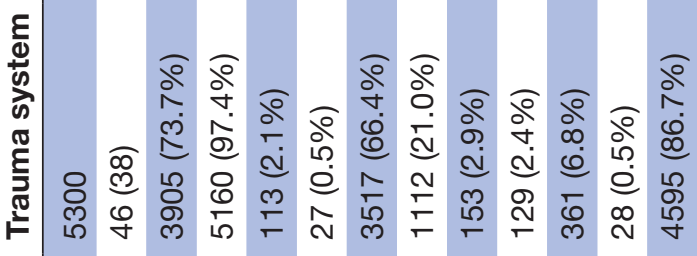

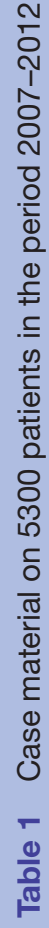

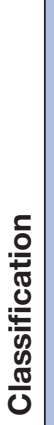

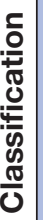

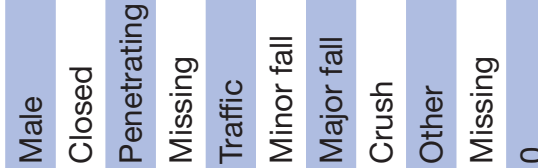

ㅇำ 岂全

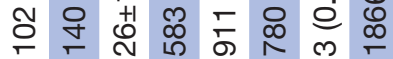

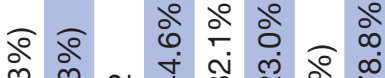
స

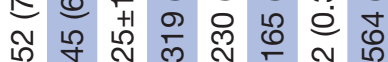

- व मे ले ले กं กี่ 드음

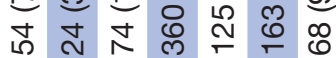

वे के वे के б m

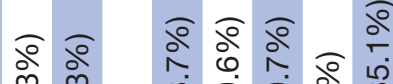
幽

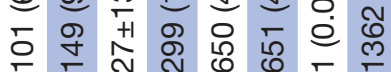

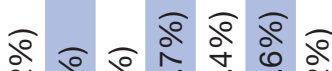
సै के ठे में

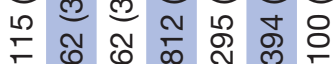

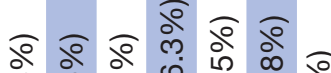
क 0 o

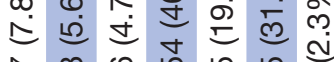
N $\stackrel{\infty}{\sim}$ 은

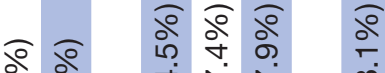
०े ले 过 e $N$ N

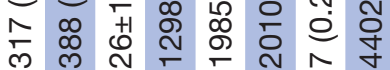

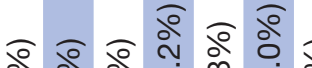

० ᄃ 잉

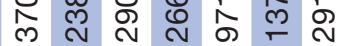

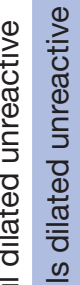

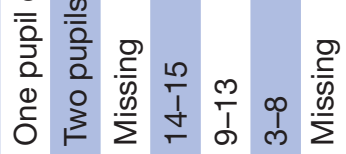

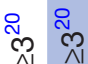
है 这 일 क $\frac{1}{2}$ क ल्र O)

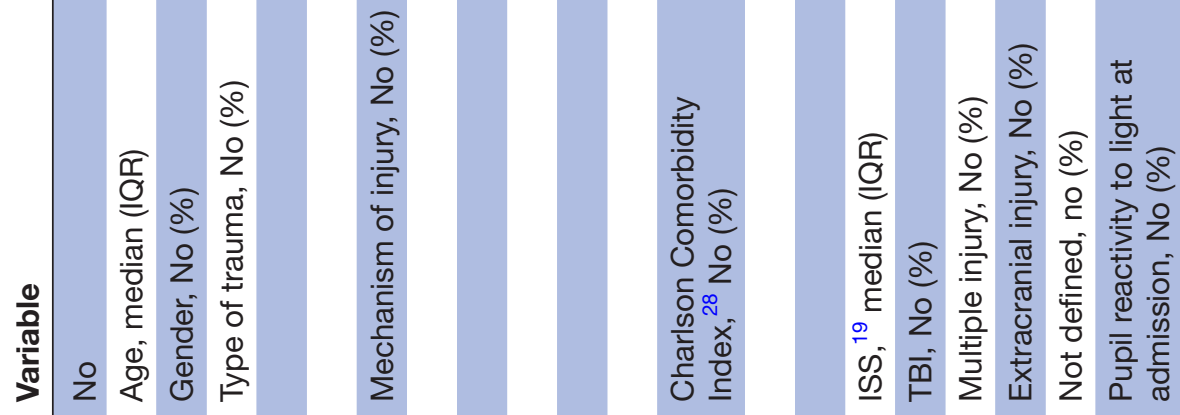

$\stackrel{\infty}{s}$

음

常

등

क़

क

을

$\vec{\omega}$

옥

음

$\stackrel{\sim}{\circ}$

옹

$\vec{G}$

인

กั

D

윰

$\stackrel{\text { N }}{\circ}$

잉

方

ֻ

$\vec{\partial}$

帚

윽

긍

$\dot{0}$

잉

웅

을.

N

กิ

Q

응

@

$\underset{0}{0}$

옴

옹

হ

윰 
with GCS $\leq 13$ were admitted to level I or neurosurgical level II TCs.

Patient distribution according to three patterns of AIS values (reported in table 2 ).

A higher proportion of all trauma system patients were admitted directly to the level I TC of Cesena (hub of the Romagna SIAT with no neurosurgical level II TC) $(1083 / 1472 ; 73.6 \%)$ compared with the level I TCs of Emilia with neurosurgical level II TCs (1905/3815; $49.9 \%$ ). In the SIAT of Emilia with no neurosurgical level II TC, the proportion of all trauma system patients directly admitted to the level I TCs (Bologna Maggiore and Parma) was relatively similar to the percentage of direct admissions to neurosurgical level II TCs $(1702 / 3815$, $44.6 \%)$.

Indirect admission was more frequent at the level I TC of Cesena (hub of the Romagna SIAT, with no neurosurgical level II TC) $(393 / 1083 ; 36.3 \%$ vs $321 / 1905 ; 16.8 \%$ at level I TCs of Emilia). Roughly half of the patients with isolated TBI were indirectly admitted to the TC of Cesena $(201 / 392 ; 51.3 \%$ vs $118 / 861 ; 23.1 \%$ at the level I TCs of Emilia). In the SIAT of Romagna, almost all indirect admissions to the level I TC of Cesena were referred from non-neurosurgical level II TCs $(346 / 393 ; 88.0 \%)$ (table 2). Conversely, the level I TCs in the Emilia SIAT indirectly admitted only a few patients from neurosurgical level II TCs $(39 / 321 ; 12.1 \%)$ (table 3 ).

\section{Standardised mortality}

Observed versus expected mortality (OE) at 30 days was not statistically different among the three types of centre with a neurosurgical unit (figure 3). However, the graphs show the progressive reduction in the mean $\mathrm{OE}$ value (meaning fewer observed deaths than expected) moving from neurosurgical level II TCs (Modena Baggiovara, Ferrara, Reggio Emilia hospitals) to the level I TCs in SIATs with additional neurosurgical units (Bologna Maggiore, Parma) and, finally, to the only level I TC in a SIAT with no neurosurgical unit (Cesena).

\section{DISCUSSION \\ Main results}

The study shows that in Emilia Romagna over half of the patients with major trauma requiring ICU care were admitted to a designated level I centre. This is testament to the adoption of good scientific practice. Only $32.2 \%$ of the patients were admitted directly to a neurosurgical level II TC.

However, the above phenomena is not consistent in the three trauma systems. While patients with isolated TBI should theoretically be admitted to level I TCs, data have shown that they are intercepted by level II TCs with neurosurgical facilities, even though they tend to be less severe. Furthermore, the percentage of patients with extracranial trauma in these centres is higher than in level I TCs but lower than in non-neurosurgical level II 
A

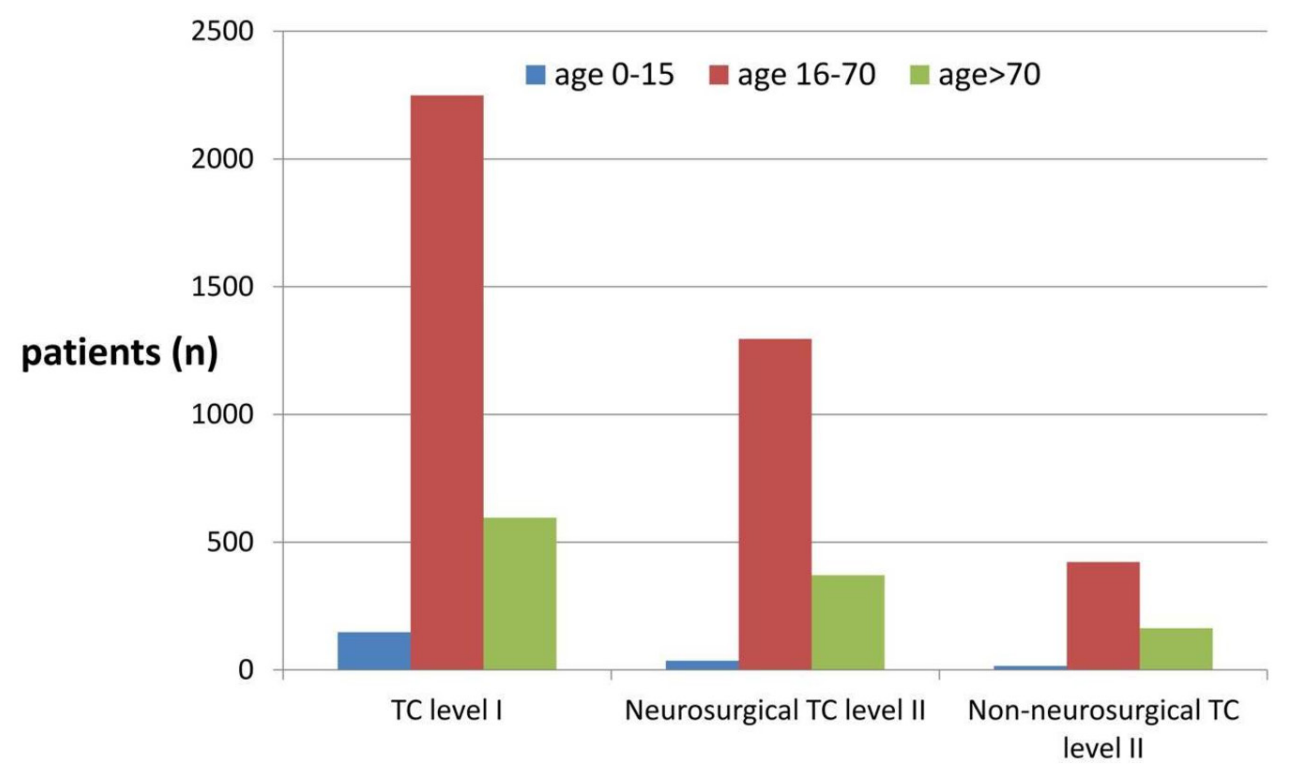

B

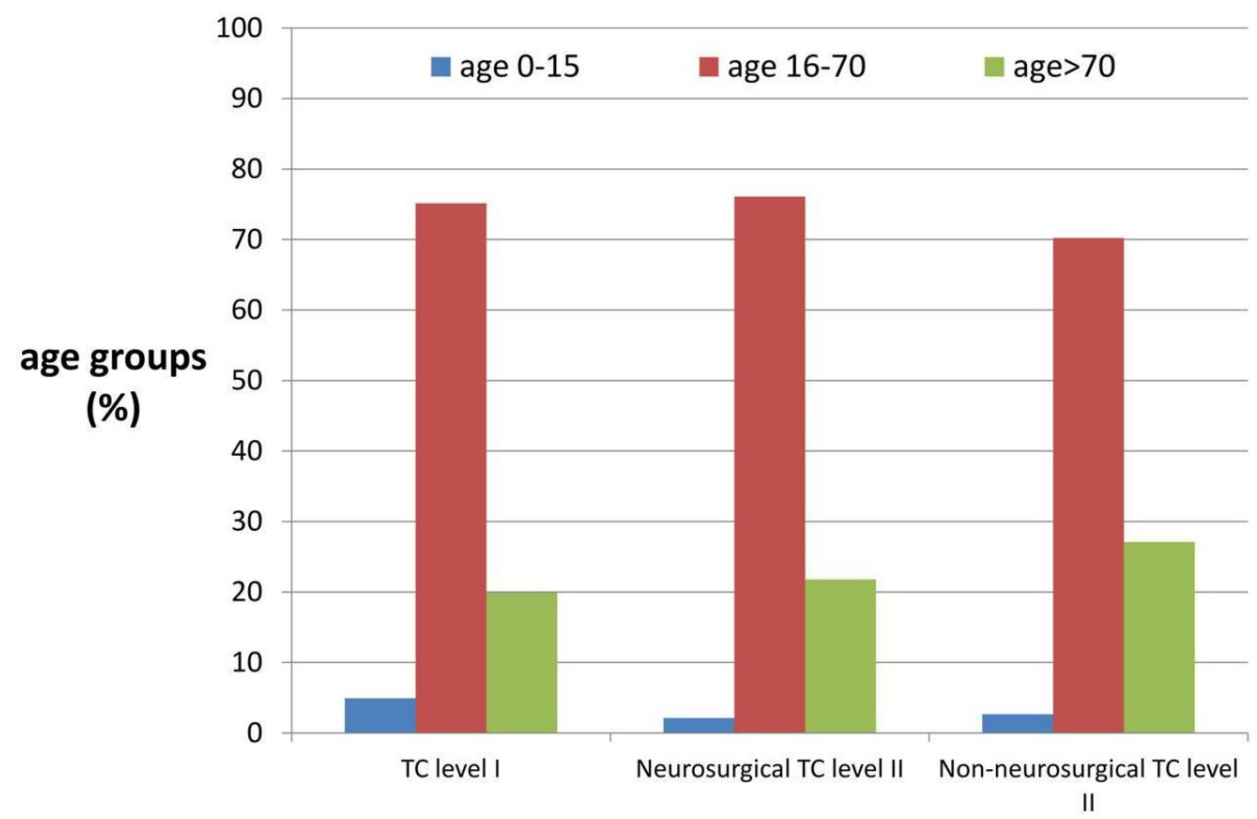

Figure 2 Patient distribution, by age, in the level I TC, the level II TC, with or without neurosurgery. Data are expressed as absolute values (A) as well as in percentage (B). TC, trauma centre.

TCs, suggesting that level II TCs with neurosurgical facilities act as surrogate level I TCs.

Fittingly, the rate of secondary referral to a level I TC for patients with TBI, be it isolated or associated with multiple injuries, was substantially higher in the SIAT with no neurosurgical level II TCs $(35.1 \%)$ than in the SIATs with a neurosurgical facility $(9.5 \%)$. The rate of centralisation in the Romagna SIAT $(35.1 \%)$ was similar to UK rates $(28.3 \%) .{ }^{30}$
The experience described in the study probably applies more to Europe than to Canadian or Australian regions, where population density is much lower, or to the USA, where exclusive trauma systems are usually headed by level I TCs. Even in Italy, the results are not easy to compare with other national data as neither the distinction between level I and II TCs nor hub-and-spoke hierarchical systems are widely adopted and no other data sets including AIS evaluation are available. The 'National 


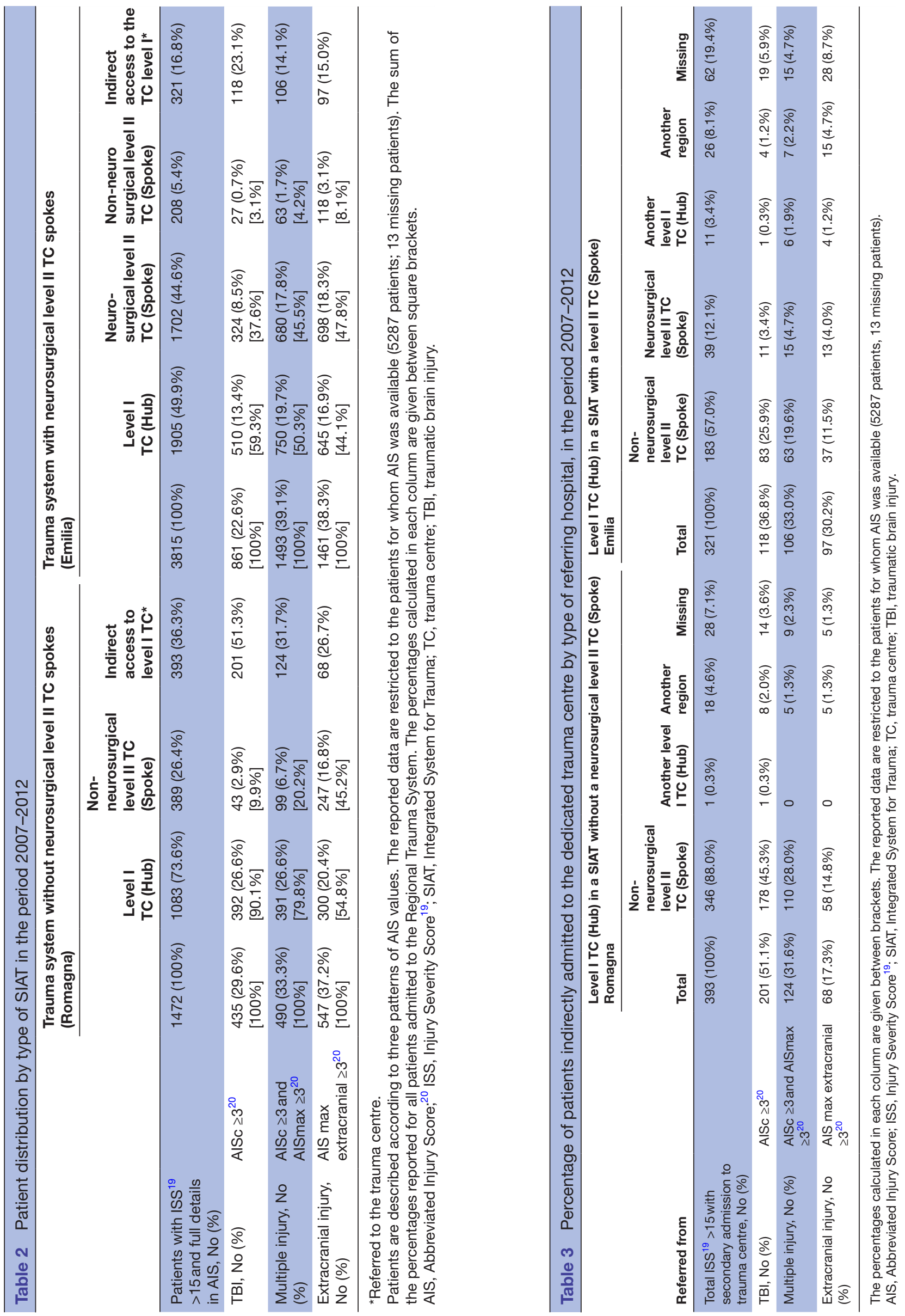




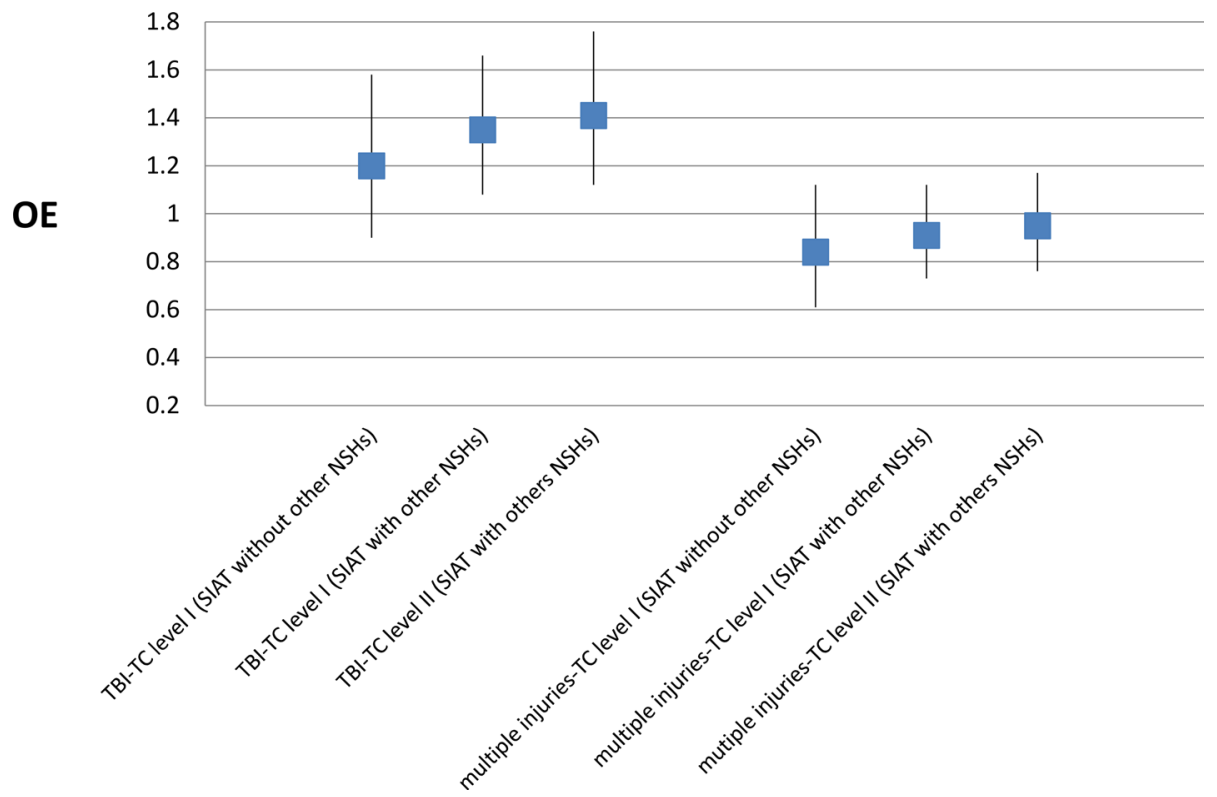

Figure 3 Comparison of 30-day observed to expected mortality (OE ratios with 95\% confidence intervals, Cl) of patients affected by predominant TBI and patients affected by multiple injuries including TBI, among (1) the level I TC (Cesena) in the SIAT (Romagna) with no other neurosurgical hospitals (NSHs); (2) the level I TC (Bologna Maggiore and Parma) in the SIATs (Emilia) with neurosurgical hospitals other than the level I TC; and (3) the level II TC (Ferrara, Modena Baggiovara, Reggio Emilia) in the SIATs (Emilia) with NSHs other than the level I TC. NSHs, neurosurgical hospitals; OE, observed to expected; SIAT, Integrated System for Trauma; TBI, traumatic brain injury.

guidelines for defining standards of hospital care', recently published in Italy, do however stress the need to establish a network of functionally linked hospital facilities based on the integrated 'hub and spoke' network model, which differentiates facilities by level of resource availability and expertise. $^{31}$

Compared with the trauma model originally designed for the Emilia Romagna region, in which level II trauma centres were entrusted with primary stabilisation of directly admitted patients, the system seems instead to have been highly influenced by the presence of other hospitals with neurosurgical units. A study conducted by the same team, ${ }^{32}$ based partly on RRTG data and partly on the Trauma Mortality Prediction Model that uses International Classification of Diseases Ninth Revision codes (TMPM-ICD9) to estimate trauma severity, ${ }^{28}$ suggested that younger and more severe patients benefited from admission to level I compared with level II TCs, irrespective of the presence or absence of a neurosurgical unit.

Our study does not adequately answer the question whether such allocation affects patient outcome since the wide confidence interval (CI) of OE ratios precludes any statistical significance. Nevertheless, the OE mortality data standardised by patient severity suggest that competition among level I and level II TCs in the same trauma system reduces performance in both. Mean performance values suggest that the level I TC working without competition from a neurosurgical level II TC performs better. Similarly, the neurosurgical level II TC competing with the level I TC in same SIAT seems to have the worst OE.
Data seem to indicate that lower competition among centres leads to more volume in level I TC and consequently to more expertise.

\section{What does the study add?}

The study shows that to design a trauma system requires capacity and ability in healthcare provision. The trauma system, based on the principle of centralisation in highvolume centres (hubs), improves prognosis, but also takes account of other aspects, as demographic and orographic characteristics and local health service organisation. Level II TCs are designated to provide primary patient stabilisation and surgery for haemorrhagic patients and to appropriately limit centralisation of patients with numerous comorbidities or who are more elderly or, generally, less expected to derive long-term benefits from more specialised care. They also have a role in night-time centralisation considering, for example, that helicopters are not permitted to fly during the hours of darkness. All these aspects justify the need for spoke centres within the inclusive hub and spoke system. The availability of neurosurgery facilities remains an important variable in final patient allocation, since it can help reduce the volume of patients centralised in level I TCs.

Development of a trauma system must considered the specific skills that can affect patient flow over other operating factors such as the centralisation protocols.

\section{Limitations}

The study did not evaluate patient-allocation factors associated with rural versus highly urbanised areas, orography, night-time restrictions or individual 
hospital resources, which can affect supply and demand. No assessment was made of local history, habitual practice prior to implementation of the trauma system or differences in the scope of the auditing process in each trauma system with regard to centralisation. As a result, the study does not explore in depth why the centralisation rate varied in the different trauma systems in the same regional organisation. The association between a higher number of neurosurgical centres and greater patient dispersion cannot therefore be considered a definitive causation. Furthermore, the study results probably also suffer from the lack of inclusion of patients with ISS $>15$ admitted to a regular ward.

The study applies to the region of Emilia Romagna. Within the Italian National Health System, healthcare is autonomously planned at the regional level, thus limiting the generalisability of the results. However, since numerous Italian regions have similar orographic and healthcare characteristics to those of Emilia Romagna, and several regions have numerous neurosurgical centres, this report could be of some help to those planning to develop trauma systems. Finally, considering the highly selected territory analysed, and the spread of standards of care, the sample size is probably not yet adequate to observe differences in performance among different subtypes of centre.

Lastly, any evaluation of patient distribution should be corroborated by an analysis linking clinical governance to an outcome. In the present study, 30-day mortality was collected and standardised, with findings suggesting that competition among centres does not help improve patient outcomes. The general limitations and strengths related to the use of standardised OE to compare trauma centre performance have been appropriately described by Shafi. ${ }^{29}$ In the present, highly selected setting, the similar basic standard of care shared by centres probably needs a more extensive sample size to detect small potential differences in outcome associated with the final allocation of different trauma patients. Conversely, waiting to collect several years of data before adjusting system organisation would not be cost-effective. Hence, by associating the data with qualitative system evaluation and expert opinion, the findings-while not statistically significant—could be sufficiently meaningful to anyone appointed to oversee clinical governance of a trauma system.

\section{CONCLUSIONS}

The study highlights that patient centralisation is per se largely driven by the availability of neurosurgical facilities. Consequently, this factor is crucial to the success of the hub and spoke system. These considerations may be helpful in the clinical governance of health services planning to implement trauma systems.

\section{ACKNOWLEDGEMENTS}

We acknowledge the contribution of Joanne Fleming in editing the manuscript. We also acknowledge the contribution of Amedeo Corsi, Alfio Gamberini, Giorgio Gambale, Mario Mergoni and Luigi Targa of the 'Gruppo di monitoraggio Assistenza al paziente con Trauma Grave (Monitoring Group for the Care of Severe Trauma Patients)' of the Emilia Romagna Region.

\section{Author affiliations}

${ }^{1}$ Neurorianimazione, ASST Grande 0spedale Metropolitano Niguarda, Milano, Italy

${ }^{2} 1$ a Anestesia e Rianimazione, Azienda 0spedaliero-Universitaria di Parma, Parma, Italy

${ }^{3}$ Rianimazione ed Emergenza Territoriale 118, Ospedale Maggiore, AUSL Bologna, Bologna, Italy

${ }^{4}$ Servizio Strutture, Tecnologie e Sistemi Informativi, Direzione Generale Cura della persona, Salute, Welfare - Assessorato alla Sanità - Regione Emilia-Romagna,

Bologna, Italy

${ }^{5}$ Area Governo Clinico, Agenzia Sanitaria e Sociale - Regione Emilia Romagna,

Bologna, Italy

${ }^{6}$ Pronto Soccorso e Coordinamento emergenze traumatologiche, Azienda Ospedaliero-Universitaria di Modena, Modena, Italy

${ }^{7}$ Pronto Soccorso e Medicina d 'Urgenza, Ospedale di Forli, Azienda AUSL di Romagna, Forli, Italy

${ }^{8}$ Pronto Soccorso e Medicina d'Urgenza, Azienda Ospedaliera Arcispedale Santa Maria Nuova-IRCCS, Reggio Emilia, Italy

${ }^{9}$ Governo Clinico - Direzione Sanitaria, Azienda USL Reggio Emilia, Reggio Emilia, Italy

${ }^{10}$ Anestesia e Rianimazione, Ospedale di Cesena, AUSL di Romagna, Emilia-

Romagna, Italy

${ }^{11}$ Anestesia e Rianimazione, Azienda USL di Piacenza, Piacenza, Italy

${ }^{12}$ UOC Cure Primarie e Specialistica S.Lazzaro-Dipartimento Cure Primarie, AUSL di Bologna, Bologna, Italy

${ }^{13}$ Servizio Assistenza Ospedaliera, Direzione Generale Cura della Persona, Salute e Welfare - Assessorato alla Sanità - Regione Emilia Romagna, Bologna, Italy

Acknowledgements We acknowledge the contribution of Joanne Fleming in editing the manuscript. We also acknowledge the contribution of Amedeo Corsi, Alfio Gamberini,Giorgio Gambale, Mario Mergoni and Luigi Targa of the "Gruppo di monitoraggio Assistenza al paziente con Trauma Grave (Monitoring Group for the Care of Severe Trauma Patients)" of the Emilia Romagna Region.

Contributors AC and RDP: idea, planning data set, data analysis, wrote the manuscript. AV, GG: planning data set, discussion of results, wrote the manuscript. CV: planning data set, data analysis, discussion of results. MB, MLRC, AF, AMF, EF, AG, MM, CM, MP, MR, ER, LT, ST: planning data set, discussion of results.

Competing interests None declared.

Ethics approval The study was not submitted to the local Ethics Committee (Comitato Etico Unico di Area Vasta Romagna, IRSST, Meldola, Italy), in accordance with its own indications. The study was observational and retrospective and was conducted on data collected according to the indications of the Italian regulatory board (Garante per la protezione dei dati personali). The data were fully anonymised and deidentified before analysis.

Provenance and peer review Not commissioned; externally peer reviewed.

Data sharing statement All data are stored in the server of the Assessorato per la Sanità della Regione Emilia Romagna, Via Aldo Moro 21, 40127 Bologna. The data will not be shared because they are properties of Regione Emilia Romagna health system. Extra data concerning patients severity and surgical intervention are available by emailing Rossana De Palma, RDePalma@Regione.EmiliaRomagna.it

Open Access This is an Open Access article distributed in accordance with the Creative Commons Attribution Non Commercial (CC BY-NC 4.0) license, which permits others to distribute, remix, adapt, build upon this work non-commercially, and license their derivative works on different terms, provided the original work is properly cited and the use is non-commercial. See: http://creativecommons.org/ licenses/by-nc/4.0/ 
(c) Article author(s) (or their employer(s) unless otherwise stated in the text of the article) 2017. All rights reserved. No commercial use is permitted unless otherwise expressly granted.

\section{REFERENCES}

1. Di Bartolomeo S, Valent F, Sanson G, et al. Are the ACSCOT filters associated with outcome? Examining morbidity and mortality in a European setting. Injury 2008;39:1001-6.

2. Franco Taggi e Pietro Marturano. "Quanto ci costa il trauma? "Salute e Sicurezza Stradale: I'Onda Lunga del Trauma. C.A.F.I. Editore, Roma 2007:565-70.

3. Automobile Club d'Italia, Anno 2013 Incidenti Stradali, novembre 2014. http://www.istat.it/it/archivio/137546ISTAT

4. ETSC (European Transport Safety Council). Annual PIN Report. 2014. http://etsc.eu/8th-annual-road-safety-performance-index-pinreport/

5. MacKenzie EJ, Rivara FP, Jurkovich GJ, et al. A national evaluation of the effect of trauma-center care on mortality. N Engl J Med 2006;354:366-78.

6. American Trauma Society. http://www.amtrauma.org/?page= TraumaLevels

7. DECRETO 2 aprile $2015, \mathrm{n}$. 70 Regolamento recante definizione degli standard qualitativi, strutturali, tecnologici e quantitativi relativi all'assistenza ospedaliera. (15G00084) (GU n.127 del 4-62015) http://www.gazzettaufficiale.it/eli/id/2015/06/04/15G00084/sg

8. Chiara O, Cimbanassi S. Organized trauma care: does volume matter and do trauma centers save lives? Curr Opin Crit Care 2003;9:510-4.

9. II portale della Regione Emilia-Romagna. http://assr.regione.emiliaromagna.it/it/aree_attivita/governo-clinico/professionisti-governo/ reti/traumatologica/trauma-link/normativa/dgr_20021267.pdf/at_ download/file/dgr_2002-1267.pdf

10. II portale della Regione Emilia-Romagna. http://assr.regione.emiliaromagna.it/it/aree_attivita/governo-clinico/professionisti-governo/ reti/traumatologica/trauma-link/siat

11. Statistica. http://statistica.regione.emilia-romagna.it/"http://statistica. regione.emilia-romagna.it

12. Chieregato A, Paci G, Portolani L, et al. Satisfaction of patients next of kin in a 'Hub \& Spoke' ICU network. Anaesthesia 2014;69:1117-26.

13. Agenzia sanitaria e sociale regionale. http://assr.regione.emiliaromagna.it/it/aree_attivita/governo-clinico/professionisti-governo/ reti/traumatologica/trauma-link/normativa/ dg_2008_136.pdf/at_ download/file/dg_2008_136.pdf

14. Fabbri A, Servadei F, Marchesini G, et al. Observational approach to subjects with mild-to-moderate head injury and initial non-neurosurgical lesions. J Neurol Neurosurg Psychiatry 2008;79:1180-5

15. Servadei F, Antonelli V, Mastrilli A, et al. Integration of image transmission into a protocol for head injury management: a preliminary report. Br J Neurosurg 2002;16:36-42.
16. II portale della Regione Emilia-Romagna. http://assr.regione.emiliaromagna.it/it/aree_attivita/governo-clinico/professionisti-governo/ reti/traumatologica/trauma-link/normativa/DG_2002_2497.pdf/at_ download/file/DG 2002 2497.pdf

17. Di Bartolomeo S, Ventura C, Marino M, et al. The counterintuitive effect of multiple injuries in severity scoring: a simple variable improves the predictive ability of NISS. Scand J Trauma Resusc Emerg Med 2011;19:26-32.

18. II portale della Regione Emilia-Romagna. http://assr.regione.emiliaromagna.it/it/aree_attivita/governo-clinico/professionisti-governo/ reti/traumatologica/trauma-link/normativa/determina_6052008.pdf/ at_download/file/determina_605-2008.pdf

19. Baker SP, O'Neill B, Haddon W, et al. The injury severity score: a method for describing patients with multiple injuries and evaluating emergency care. J Trauma 1974;14:187-96.

20. Osler T, Baker SP, Long W. A modification of the injury severity score that both improves accuracy and simplifies scoring. J Trauma 1997;43:922-6.

21. Walder AD, Yeoman PM, Turnbull A. The abbreviated injury scale as a predictor of outcome of severe head injury. Intensive Care Med 1995;21:606-9.

22. Lesko MM, Woodford M, White L, et al. Using Abbreviated Injury Scale (AIS) codes to classify Computed Tomography (CT) features in the Marshall System. BMC Med Res Methodol 2010;10:72.

23. Ross SE, O'Malley KF, Stein S, et al. Abbreviated injury scaling of head injury as a prognostic tool for functional outcome. Accid Anal Prev 1992;24:181-5.

24. Demetriades D, Kuncir E, Murray J, et al. Mortality prediction of head Abbreviated Injury Score and Glasgow Coma Scale: analysis of 7,764 head injuries. J Am Coll Surg 2004;199:216-22.

25. Teasdale G, Jennett B. Assessment of coma and impaired consciousness. A practical scale. Lancet 1974;2:81-4.

26. Miller JD. Minor, moderate and severe head injury. Neurosurg Rev 1986;9:135-9.

27. Gagne JJ, Glynn RJ, Avorn J, et al. A combined comorbidity score predicted mortality in elderly patients better than existing scores. J Clin Epidemiol 2011;64:749-59.

28. Di Bartolomeo S, Ventura C, Marino M, et al. Is the TMPM-ICD9 revolution in trauma risk-adjustment compatible with imperfect administrative coding? Accid Anal Prev 2011;43:1955-9.

29. Shafi S, Nathens AB, Parks J, et al. Trauma quality improvement using risk-adjusted outcomes. J Trauma 2008;64:599-606.

30. Gabbe BJ, Biostat GD, Lecky FE, et al. The effect of an organized trauma system on mortality in major trauma involving serious head injury: a comparison of the United kingdom and victoria, australia. Ann Surg 2011;253:138-43.

31. Chiara O. Sistema integrato per l'assistenza al trauma maggiore: definizione e valutazione di un modello organizzativo. Consiglio Superiore di Sanità, Ministero della Salute, Roma, 2004.

32. Di Bartolomeo S, Marino M, Ventura C, et al. Evaluation of the survival benefit of Trauma-Centre care in the Italian setting. Injury 2014;45:299-303. 